\title{
The Effeet of Using Active Learning on the Performance Level of the Long Jump Event in the Stepping - in - Air Method in Students of the Faculty of Physical Education, Alexandria.
}

\author{
Abir Muawad Mohamed Abdallah \\ School Sport Department, Faculty of Physical Education for Boys, Alexandria University, Egypt. \\ Mohamed Abdel Wahah Ateya \\ School Sport Department, Faculty of Physical Education for Boys, Alexandria University, Egypt.
}

\begin{abstract}
The study aims to find out the effect of the use of active learning strategy of cooperative learning on the level of performance of the long jump event in a way to stepping - in - air method for the first year students at the Faculty of Physical Education, for Boys in Alexandria. The experimental method was used to design the pilot study of the two groups, one experimental and the other officer using pre-and post-measurements test for the two groups on a sample of (24) students of the first at the Faculty of Physical Education, for the academic year 2012/2013. The sample was divided into two groups, each group (12 students).The researchers found that the use of active the learning strategy of cooperative learning led to raising the level of performance of the students of the experimental group in the jump event stepping long way in the air and was more influential than traditional learning style (orders) for the control group in learning the long jump event in a way to step into the air.
\end{abstract}

\section{Introduction:}

$\mathrm{T}$ The progress of sport in a nation is a proof of its scientific progress. Countries of the world compete in all fields of science and technology. Education is the mainstay of every progress made and the means to cope with the advancement of civilization. In their efforts to achieve the goals and objectives of the educational process, the educational institutions endeavor to support the latest strategies and methods of education in such a manner as to enrich the process and make it more compatible with scientific progress. (3: 6)

An efficient teacher would always have something new to present, and know several approaches to direct and indirect teaching. He or she would encourage learners to explore and research through positive participation in the teaching process. (1:9)

The comprehensive method of education is based on the teacher-learner and learner-learner interaction. The conventional teaching method of presenting material by the teacher and receiving it by the learner, involving commanding by the teacher and obedience by the learner is a passive method which cannot result in true learning. This made a case for the need to develop teaching methods and strategies and shifting from passive to active learning that would push the learner forwards to think about what he or she has leaned. The term Active Learning was used in the last years of the $20^{\text {th }}$ century and gained a growing interest in the opening years of the $21^{\text {st }}$ century as one of the modern trends in education and the learning process. $(2-3)$

Active learning is both a teaching and learning method in which students participate in activities, exercises and projects more effectively in a rich environment of diversity that helps them positively listen and share in a constructive dialogue, based on careful thinking and sound analysis of material read and learnt. The teacher's role is to encourage them to bear the responsibility of self-teaching under his or her supervision, and drive them forwards to achieve the objectives of the curriculum which should be focused on building an integrated, creative personality of today's student and tomorrow's man. (10-33)

Active learning strategies are numerous and according to the National Educational Research Centre there are ten such strategies (2006). The cooperative leaning strategy was chosen by the authors of this paper as one of the active learning strategies that can improve the performance level of the long jump event in the stepping in - air method.

The research problem is how to improve the low profile of the performance level of the long jump event in the stepping - in - air method among the first year students in the Faculty of Physical Education for Boys, Alexandria. Results of the final examination of the subject (track and field events teaching methods) showed that students got low marks and could not perform the correct model of the long jump event in the stepping - in - air method. 
The problem was attributed by the authors to the fact that students learn the subject in a method based on giving commands by the teacher and accurately carrying them out by the student with no thinking whatsoever on the part of the latter. The solution suggested by the authors of this paper consisted in using active learning (the cooperative learning strategy) to encourage students to effectively share in the teaching-learning process, thus enhancing their performance of the sport.

Active learning is a new teaching method that can help improve the teaching process. According to Hassan Zeitoun (2006), definitions of cooperative learning are numerous. One of these defines the method as a kind of class effective learning in which the class is divided into small cooperative groups. The class is utilized to develop both academic achievement and social skills, and is divided into cooperative groups ( $2-6$ students). Groups are heterogeneous in academic abilities, including excellent, average and weak learners, and all the members of the group are asked to take part in carrying out the task at hand, through discussions, sharing experiences and mutually providing feedback. Work can be distributed to all members of the group, and once part of the task is completed, experiences are exchanged. This creates a sense of being responsible not only for one's part of the task, but for the success of the whole task done by the group. (5:246-247)(12:1-2)

Long jump is practiced by men and women alike. It is a simple and easy to perform motor activity, especially in the early stages of education. It is also common and popular not only in the track and field events, but in various sport games and activities as well. School children do it unguided by teachers, and compete unaware of kinetics and the special techniques required for performance. The practice helps develop the flight power as a result of the repeated jumping across the pit, hence the importance of the long jump as physical activity. Bastawisi Ahmed (2005) suggested that the length of the jump distance depends on the outcome of horizontal speed resulting from approaching and vertical speed as a result of mounting. The faster the speed of approaching and mounting, the faster the starting speed and the longer the jumping distance.There is consensus on the technical stages of the long jump as: 1) approaching; 2) mounting; 3)flight; and 4) landing. (4-288)

\section{Objective of the study}

The study aims at identifying the effect of using active learning, represented in cooperative learning strategy on the performance level of the long jump event in the stepping - in - air method in students of the Faculty of Physical Education for Boys, Alexandria.

\section{Hypotheses}

1. There are statistically significant differences between pre-measurements and postmeasurements in tests of the performance level of the long jump event in the stepping - in - air method in the experimental group, favoring post measurements.

2. There are statistically significant differences between pre-measurements and postmeasurements in tests of the performance level of the long jump event in the stepping - in - air method in the control group, favoring post measurements

3. There are statistically significant differences between the two post-measurements in tests of the performance level of the long jump event in the stepping - in - air method in the experimental and control groups, favoring the experimental group.

The use of active learning strategies in instruction was addressed by a number of studies such as the study by Mohamed Hindy (2002)(9) which concluded that the use of the strategy resulted in the acquisition by students of the habit of mutual dependence. Another study by Keller (2002)(15) showed that active learning based on problem solving had a positive effect on school achievement. The study by Abdel Rahman (2007)(7) found that the brain storming and problem solving groups surpassed groups using other strategies. Hiba el Shobokshy's study (2007)(14) proved that teaching using active learning had a positive effect on cooperative attitudes in pupils and helped them acquire scientific concepts. The study by Amany el-Sayed (2009(3) found that active learning had an effect on enhancing school achievement and developing creative thinking. Tandogan's study (2007)(16) proved that the use of active learning based on problem solving increased conceptual development in students using this strategy.

\section{Study procedures}

\section{Methodology}

The experimental method was used, with premeasurements and post-measurements taken from two groups (one experimental and the other a control group).

\section{Study sample}

The study was conducted on a sample of 24 first year students in the Faculty of Physical Education for Boys, Alexandria University. The sample was randomly chosen and was divided into two groups: the active learning based on the cooperative learning strategy was applied to the experimental group $(\mathrm{N}=12)$, while the conventional 
teaching method in teaching the track and field events subject (the command method) was used with the other group ( $\mathrm{N}=12)$. Tables 5, 6 and 7 (Attachment 1) show homogeneity of the sample in the primary variables (age, height and weight), the physical abilities and skill tests in the long jump event. Equivalence of the two research groups was conducted through tables 8, 9 and 10 (Attachment2).

\section{Study tools}

\section{Physical ability tests}

Tests of physical abilities were used as recommended in scientific references (11)(2000), (8)(2001) (Attachment 4). Coefficients of the were found to ensure validity and reliability of the tests on a sample of 14 students other than the research sample subjects as stated in tables 11 and 12 (Attachment 3).

2. II. Evaluating the performance level of the long jump in the stepping-in air method

This was done in two ways:

1. The skillful (digital) test of the long jump in the stepping-in air method (Attachment 5)

2. The performance observing card of the long jump in the stepping-in air method. The card was designed and submitted to experts for comments (Attachment 7) and changes were accordingly introduced so that the card came out in its final form (6) the validity of the observation form was calculated by judges who approved it with a percentage of $100 \%$. Reliability was found to be 0.89 .

\section{Development of the active learning programme for the experimental group}

- the learning module (for the long jump in the stepping-in air method) was designed for the experimental group using the cooperative learning strategy as follows:

- $\quad$ the long jump in the stepping-in air method was taught using the cooperative learning strategy in papers. Working papers contained the basic part of the lesson (instructional and applied components of the module).

- The module content of the long jump in the stepping-in air method was distributed over 8 lessons during the basic experiment of the research, at the rate of 2 lessons per week, for 4 weeks.

- The time allocated for each lesson was 90 minutes, with 40 minutes as a basic portion which was the time given to the experimental variable in the cooperative learning strategy and the conventional (command) method.

The active learning programme was submitted to curriculum and teaching methods experts for their comments (Attachment 9). The experimental control factors were taken into consideration between the two groups in the experimental variables concerned with designing learning modules. The total time of the two groups and the time allocated for portions of the lesson were consolidated. Contents of the modules and potentials were also consolidated. The only difference was in the strategy followed. The time distribution of the leaning module for the two groups is shown in table 1.

Table 1

\begin{tabular}{|c|c|c|}
\hline lesson portions & time & Work \\
\hline administrative work & 15 minutes & recording attendance + preparing field and equipment \\
\hline Warm-up and physical preparation & 20 minutes & physical preparation exercises for the long jump event \\
\hline instructional and applied activity & 40 minutes & $\begin{array}{c}\text { the long jump event teaching in the active learning and } \\
\text { conventional methods }\end{array}$ \\
\hline Conclusion & 15 minutes & cooling down and re-storing equipment - leaving \\
\hline Total & 90 minutes & \\
\hline
\end{tabular}

\section{Pilot study}

The pilot study was conducted in the period from $13 / 10 / 2012$ to $15 / 10 / 2012$ on a group of the first year students not included in the research sample, with the following aims:

1. training the assistants in teaching using active learning strategies (cooperative learning);
2. determining the appropriateness of the equipment used in teaching;

3. detecting difficulties that may arise while applying the programme;

4. identifying how each student understands his role through the task and standard sheet of the active leaning group (cooperative learning). 


\section{Pre-measurements}

Pre-measurements were taken in the period from $16 / 10 / 2012$ to $18 / 10 / 2012$ in order to measure the research variables.

\section{Basic study}

The pilot study was conducted in the period from $21 / 10 / 2012$ to $22 / 11 / 2012$ because the track and field subject is taught in the first term of the academic year.

\section{Post-measurements}

Post-measurements were taken in the period from $24 / 11 / 2012$ to $26 / 11 / 2012$.

Table 2

Significance of differences between pre-measurement and post-measurement in the experimental group in tests of the performance level of the long jump even in the stepping-in-air method for first year students of the Faculty of Physical Education for Boys, Alexandria University $(\mathrm{N}=12)$

\begin{tabular}{|c|c|c|c|c|c|c|c|}
\hline \multirow[t]{2}{*}{ Statistical treatment } & \multicolumn{2}{|c|}{ Post-measurement } & \multicolumn{2}{|c|}{ Pre-measurement } & \multirow{2}{*}{$\begin{array}{c}\text { Average } \\
\text { differences }\end{array}$} & \multirow{2}{*}{$\begin{array}{l}\text { Average } \\
\text { standard } \\
\text { deviation }\end{array}$} & \multirow{2}{*}{$\begin{array}{c}\text { Calculated } \\
\text { T value }\end{array}$} \\
\hline & means & $\begin{array}{l}\text { standard } \\
\text { deviation }\end{array}$ & means & $\begin{array}{l}\text { standard } \\
\text { deviation }\end{array}$ & & & \\
\hline long jump test (m) & 4.42 & 0.77 & 3.98 & 1.25 & 0.18 & 0.35 & $* * 5.87$ \\
\hline $\begin{array}{l}\text { Evaluating the performance level of } \\
\text { the long jump in the stepping-in air } \\
\text { method (scores) }\end{array}$ & 13.42 & 1.16 & 8.92 & 1.39 & 4.5 & 2.54 & $* * 8.89$ \\
\hline
\end{tabular}

* the tabular $\mathbf{T}$ value at the 0.05 level $=\mathbf{2 . 0 7}$

$* * 0.01=2.81$

Table 2 shows statistically significant differences at the 0.01 level between pre-measurements and postmeasurements in tests of the performance level of the long jump event in the stepping - in - air method in the

Table 3

Significance of differences between pre-measurement and post-measurement in the control group in tests of the performance level of the long jump even in the stepping-in-air method for first year students of the Faculty of Physical Education for Boys, Alexandria University $(\mathrm{N}=12)$

\begin{tabular}{|c|c|c|c|c|c|c|c|}
\hline \multirow{2}{*}{ Statistical treatment } & \multicolumn{2}{|c|}{ Post-measurement } & \multicolumn{2}{|c|}{ Pre-measurement } & \multirow{2}{*}{$\begin{array}{c}\text { Average } \\
\text { differences }\end{array}$} & \multirow{2}{*}{$\begin{array}{l}\text { Average } \\
\text { standard } \\
\text { deviation }\end{array}$} & \multirow{2}{*}{$\begin{array}{c}\text { Calculated } \\
\text { T value }\end{array}$} \\
\hline & means & $\begin{array}{r}\text { standard } \\
\text { deviation }\end{array}$ & means & $\begin{array}{c}\text { standard } \\
\text { deviation }\end{array}$ & & & \\
\hline long jump test (m) & 4.203 & 1.85 & 3.89 & 1.28 & 0.30 & 1.29 & $* * 4.67$ \\
\hline $\begin{array}{c}\text { Evaluating the performance level of } \\
\text { the long jump in the stepping-in air } \\
\text { method (scores) }\end{array}$ & 11.333 & 1.39 & 8.17 & 1.24 & 3.17 & 2.12 & $* * 6.59$ \\
\hline
\end{tabular}

* the tabular $\mathbf{T}$ value at the 0.05 level $=\mathbf{2 . 0 7}$

** $0.01=2.81$

Table 3 shows statistically significant differences at the 0.01 level between pre-measurements and postmeasurements in tests of the performance level of the long jump event in the stepping - in - air method in the control experimental group of the first year students at the Faculty of Physical Education, for Boys in Alexandria, favoring post measurements.
- the arithmetic mean

- median

- $\quad$ skewness coefficient

\section{1. result presentation}


Table 4

Significance of differences between the two post-measurements in the experimental and control groups in tests of the performance level of the long jump even in the stepping-in-air method for first year students of the Faculty of Physical Education for Boys, Alexandria University $(\mathrm{N}=12)$

\begin{tabular}{|c|c|c|c|c|c|c|c|}
\hline \multirow[t]{2}{*}{ Statistical treatment } & \multicolumn{2}{|c|}{ Post-measurement } & \multicolumn{2}{|c|}{ Pre-measurement } & \multirow{2}{*}{$\begin{array}{c}\text { Average } \\
\text { differences }\end{array}$} & \multirow{2}{*}{$\begin{array}{l}\text { Average } \\
\text { standard } \\
\text { deviation }\end{array}$} & \multirow{2}{*}{$\begin{array}{l}\text { Calculated } \\
\mathrm{T} \text { value }\end{array}$} \\
\hline & means & $\begin{array}{r}\text { standard } \\
\text { deviation }\end{array}$ & means & $\begin{array}{c}\text { standard } \\
\text { deviation }\end{array}$ & & & \\
\hline long jump test (m) & 4.42 & 0.77 & 4.20 & 1.85 & 0.214 & 1.54 & $* 2.63$ \\
\hline $\begin{array}{l}\text { Evaluating the performance level of } \\
\text { the long jump in the stepping-in air } \\
\text { method (scores) }\end{array}$ & 13.42 & 1.16 & 11.33 & 1.39 & 2.08 & 1.98 & $* * 5.60$ \\
\hline
\end{tabular}

* the tabular $\mathbf{T}$ value at the 0.05 level $=\mathbf{2 . 0 7}$

\section{** $0.01=2.81$}

Table 4 shows that there are statistically significant differences in all post-measurements in tests of the performance level of the long jump event in the stepping in - air method in the experimental and control groups, favoring the experimental group.

\section{Result discussion}

Table 2 shows statistically significant differences between pre-measurements and post-measurements in tests of the performance level of the long jump event in the stepping in - air method in the experimental group of the first year students at the Faculty of Physical Education for Boys in Alexandria. The calculated $\mathrm{T}$ value $(5.87,8.89)$ was greater than the tabular $\mathrm{T}$ value $(2.07,2.81)$ at the level 0.05 and 0.01 . The difference is attributable to the use of active learning strategy based on cooperative learning which had an important positive effect on the performance level of the long jump event in the stepping-in-air method because it depends on the participation of the learner in the learning process. Each learner has a role to play within the cooperative group. Every member of the group must work for the final goal which requires that each member learn the correct performance of the long jump event in the stepping-in-air method. This also conforms with results reached by Ahmed Hussein (1990)(2:151) and Mohamed el-Deeb (2007)(1: 2-12), who stated that giving small groups of learners the opportunity to cooperate and share advice has the greatest effect on improving the motor performance level. This proves the first hypothesis of the present study.

Table 3 shows statistically significant differences at the 0.01 level between pre-measurements and postmeasurements in tests of the performance level of the long jump event in the stepping - in - air method in the control group of the first year students at the Faculty of Physical Education, for Boys in Alexandria, favoring post measurements. The calculated $\mathrm{T}$ value $(4.67,6.59)$ was greater than the tabular $\mathrm{T}$ value $(2.07,2.81)$ at the level 0.05 and 0.01 . The difference is attributable to the use of the conventional method of command, depending on the teacher in all stages and the teacher is the person responsible for planning, implementation and evaluation. The learner is passive and has only to obey orders and do what he is asked to do. This proves the second hypothesis of the present study.

Table 4 shows that there are statistically significant differences in all post-measurements in tests of the performance level of the long jump event in the stepping in - air method in the experimental and control groups, favoring the experimental group. The calculated $\mathrm{T}$ value (2.63, 5.60) was greater than the tabular $\mathrm{T}$ value $(2.07$, 2.81 ) at the level 0.05 and 0.01 . Volume of the effect was great because the value ranged between 0.72 and 1.62 . The difference is attributable to the use of active learning strategy based on cooperative learning which is a basic means to bring about the positive effect in the performance level of the long jump event in the steppingin-air method because it depends on the participation of the learner in the learning process and the interdependence of members of the same group to achieve specific aims. This conforms with results reached by Mhamed Hindy (2002)(13) who stressed the importance of the use of active learning strategies which helps learners acquire the habit of mutual dependence and perform the motor skills properly.

In the light of the study results, the following conclusions were made:

1. The use of active learning based on the cooperative leaning strategy had a great effect on learning the long jump event in the steppingin-air method. Thus raising the performance level among the experimental group members of the first year students at the Faculty of Physical Education, for Boys in Alexandria.

2. The use of the conventional teaching method in teaching the track and field events subject (the command method) had a great effect on learning the long jump event in the stepping-in-air method. Thus raising the performance level 
among the experimental group members of the first year students at the Faculty of Physical Education, for Boys in Alexandria.

3. The use of active learning with the experimental group was more effective than the use of the conventional teaching method in learning the long jump event in the stepping-in-air method and in the performance level of the event.

\section{Recommendations}

1. The active learning method based on the cooperative leaning strategy should be used in teaching the first year students at the Faculty of Physical Education, for Boys in Alexandria the long jump event in the stepping-in-air method because it proved to be effective in this respect.

2. Further research should be conducted in the same venue on other track and field events.

\section{References}

\section{Arabic References}

1. Ahmed Hussein el Lakkany and Aly el Gamal (1996): Dictionary of cognitive educational terminology in curricula and teaching methods. Dar Al Fikr Al Araby, $1^{\text {st }}$ edition.

2. the national centre for educational research and development (2006): evaluating the active learning experience in primary schools in Egypt, Cairo.

3. Amany el Sayed Farghaly Selim (2009): The effect of active learning in developing creative thinking and school achievement in pupils of the first phase of basic education, unpublished thesis for the Master's degree, institute of educational studies, Cairo University.

4. Bastawisi Ahmed (2005) track races and field events (instruction, technique, training), $1^{\text {st }}$ edition, Dar Al Fikr Al Araby.

5. Hassan Hussein Zeitoon (2006) teaching strategies, a contemporary view of teaching and learning methods, $1^{\text {st }}$ edition, Alam Al Kotob, Cairo.

6. Khaled Abdel Morgan Abdel Dayem (1996): the effect of using some learning methods on the performance level of vaulting for beginners, unpublished dissertation for the PH. D, degree, Faculty of Physical Education, for Boys, Zagazig University.

7. Abdel Rahman Kamel Mahmoud (2007): the effect of some active learning strategies and realistic evaluation in developing the written composition skills in first year pupils of the preparatory stage of education, studies on curricula and teaching methods, No 129.

8. Mohamed Hassan Allawi and Mohamed Nasr el Din Radwan (2001):motor performance tests, Dar Al Fikr Al Araby, Cairo.

9. Mohamed Hammad Hindy (2002): the effect of diversifying active learning on acquiring some biological concepts, self-esteem and interdependence among first year students of the secondary agricultural education, studies on curricula and teaching methods, No 79.

10. Mohamed Saleh Abdel Samie (2008): compiling a suggested portofolio in art education based on active learning strategies for teaching art appreciation to students of the preparatory stage of education, unpublished dissertation for the PH. D, degree, Faculty of Art Education, Helwan University.

11. Mohamed Sobhy Hassanein (2000): Measurement and evaluation in physical Education, part II, $4^{\text {th }}$ edition, Dar Al Fikr Al Araby, Cairo.

12. Mohamed Mostafa el Deeb (2007): Modern strategies in cooperative learning, Alam Al Kotob, Cairo.

13. Mahmoud el Rabiee Dawood (2008): cooperative learning strategies, Al Maysara publication House, Amman, Jordan.

14. Biba galal el Sayed el Shobokshy (2007): the effect of using active learning strategies on the acquisition of scientific concepts in the science and developing cooperative attitudes among preparatory school pupils, unpublished thesis for the Master's degree, Faculty of Physical Education, Zagazig University.

\section{English References}

15. Keller, G, E, (2002): Using problem based and active learning an inter - disciplinary science course for non - science .

16. Tandogan,R,\&,Akinoglu, O. (2007): "the Effects of problem based active learning in science education on students' academic achievement , attitude and conceptlearning" on line submission , Eurasia journal of mathematics, Science and Technology Education,vol.3 No.1,pp.77-81,Eric.no :Ej752356 
